Flujos migratorios en el sur de Chiapas: una narrativa local del impacto de las caravanas migrantes y los grupos africanos ${ }^{1}$

Migratory flows in southern Chiapas: a local narrative of the impact of migrant caravans and African groups

Cándido, Chan-Pech' ${ }^{2}$

Universidad Autónoma de Chiapas, México

https://orcid.org/0000-0003-0030-0313

\title{
RESUMEN
}

El presente artículo es una revisión documental cuyo objetivo es presentar una narrativa que plantea el impacto de la migración que se está dando en la ciudad de Tapachula, Chiapas. Se aplicó el método cualitativo y en particular el etnográfico utilizando como técnica de investigación la revisión documental, considerando como insumo las narrativas locales encontradas en las noticias, reportajes y artículos que los periódicos locales generan. Se parte de la narrativa cronológica de la migración centroamericana a través de las caravanas, y los grupos de África-caribeños los cuales están impactando en dimensiones como la cotidianeidad de la vida local y la mutación de las formas y maneras de migrar, todo ello en el periodo de octubre 2018- septiembre 2019. Se encontró que desde el año pasado el flujo de migrantes ha aumentado exponencialmente provocando una serie de interrelaciones culturales que están reconfigurando la cotidianidad; emergiendo así nuevas realidades y culturas como las muestras de xenofobia y discriminación que se están dando dentro de una política strictu sensu implementada desde el mismo gobierno. Se concluye con el planteamiento del nacimiento de una comunidad africana atrapada, avizorando nuevas crisis latentes en la cotidianidad.

Palabras claves: caravanas migrantes, migración africana, migración centroamericana y narrativas locales.

\begin{abstract}
This article is a documentary review whose objective is to present a narrative that raises the impact of the migration that is taking place in the city of Tapachula, Chiapas. The qualitative method and in particular the ethnographic method were applied using the documentary review as a research technique, considering as input the local narratives found in the news, reports and articles that the local newspapers generate. It is based on the chronological narrative of Central American migration through the caravans, and the African-Caribbean groups which are impacting on dimensions such as the daily life of local life and the mutation of the forms and ways of migrating, all in the period from October 2018- September 2019. It was found that since last year the flow of migrants has increased exponentially causing a series of cultural interrelations that are reconfiguring everyday life; emerging new realities and cultures as the examples of xenophobia and discrimination that are taking place within a strictu sensu policy implemented from the same government. It concludes with the approach to the birth of a trapped African community, seeing new latent crises in everyday life.
\end{abstract}

Keywords: African migration, Central American migration, migrant caravans, and local narratives

Recibido: 18 de Enero 2019 - Aceptado: 12 de Abril 2019

Cómo referenciar este artículo:

Chan-Pech, C. (2019). Flujos migratorios en el sur de Chiapas: una narrativa local del impacto de las caravanas migrantes y los grupos africanos . Revista Política, Globalidad y Ciudadanía, 43-62. Recuperado de http:// revpoliticas.uanl.mx/index.php/RPGyC/article/view/123

$1 \quad$ Artículo de revisión derivado del proyecto de investigación: Gobernanza y Políticas migratorias en el sur de Chiapas financiado por la Escuela de Humanidades y el Centro de Investigación con Visión Mesoamericana de la Universidad Autónoma de Chiapas.

2 Doctor en Pedagogía Crítica y Educación Popular por el Instituto Mclaren de Pedagogía Crítica., Profesor de Tiempo Completo, Escuela de Humanidades C-IV, y el Centro de Estudios con visión Mesoamericana, de la Universidad Autónoma de Chiapas. Email: c.chan@ live.com.mx

Revista Política, Globalidad y Ciudadanía, Vol. 5 No. 10, Julio - Diciembre 2019, Universidad Autónoma de Nuevo León, Monterrey, México, ISSN 2395-8448. 43-62. http://revpoliticas.uanl.mx/index.php/RPGyC/article/view/123 


\section{1.- INTRODUCCION}

Después de observar casi un año la inusual migración que se inició en octubre de 2018, donde miles de centroamericanos formaron caravanas masivas en la frontera con México, se registró un rio humano entre 7 y 10 mil personas que recorrió las carreteras, ocupando parques y espacios públicos.

En el marco de esta percepción, se generó una inquietud ante una realidad cambiante determinada por la migración que dio origen al cuestionamiento de ¿cómo está impactando esta serie de éxodos masivos en la vida cotidiana, económica y social de Tapachula Chiapas? Este planteamiento se origina considerando que es la primera vez que México enfrenta un comportamiento inédito en el flujo migratorio centroamericano, especialmente el número de hondureños que han abandonado su país con destino a Estados Unidos pasando por México, al tiempo que creció también de manera inédita la proporción de mujeres y menores de edad. Aunado a ello se está dando el flujo de los llamados "migrantes extracontinentales", que vienen fuera del continente americano, particularmente de África y Asia y que han arribado en cantidades inusuales, sin olvidar el caso de los cubanos, que desde 2016 empezaron su éxodo desde Nicaragua, otros desde Venezuela o Ecuador, además de los congoleños, angoleños y haitianos que están varados en espera de un salvoconducto para cruzar el país.

El abordaje de este fenómeno migratorio es pertinente toda vez que incide en las políticas públicas de atención a la migración en el sentido de que a partir del Marco de Gobernanza sobre la migración propuesto por la Organización Internacional de la Migración (OIM, 2018) se pueden advertir graves problemas en la puesta en marcha de los principios reguladores de la migración. Es importante reconocer que, aunque son los primeros éxodos masivos, esto es ya una realidad constante toda vez que se tiene que considerar que el sur de Chiapas es por su ubicación geográfica un espacio fronterizo y por lo tanto existe una importancia geopolítica. Estos éxodos están irrumpiendo en la vida cotidiana de los habitantes provocando un impacto en todos los ámbitos de la vida económica, social y cultural dando lugar a un cambio, una reconfiguración y recomposición de los imaginarios y representaciones sociales en la región, promovido y continuado por las políticas de restricción migratoria, las cuales para Roberto S. Aruj (2008) se pueden asumir como políticas strictu sensu, una política de contención más que de control, dictadas por las políticas del actual gobierno de Trump.

Lo planteado en este estudio, todavía es a modo de radiografía inicial para profundizar en nuevas aproximaciones sobre el impacto a largo plazo, la posibilidad de una crisis humanitaria, la atención a una comunidad africana atrapada, y el análisis del crecimiento exponencial y su impacto en la educación, la salud y la seguridad.

\section{2.- FUNDAMENTO TEÓRICO}

DuraLa migración es un fenómeno global con impactos contradictorios y complejos; por un lado, impulsa el crecimiento económico, reduce las desigualdades, conecta sociedades diferentes y ayuda a la movilidad demográfica del crecimiento y el declive de la población; por otro

Revista Política, Globalidad y Ciudadanía, Vol. 5 No. 10, Julio - Diciembre 2019, Universidad Autónoma de Nuevo León, Monterrey, México, ISSN 2395-8448. 43-62. http://revpoliticas.uanl.mx/index.php/RPGyC/article/view/123 
lado provoca conductas racistas xenofóbicas, discriminación y a veces violencia (Aruj, 2008). El impacto de la migración ha sido motivo de estudio, calculando el coste de las políticas de migración, la mano laboral y el aumento del consumo, y el mantenimiento de la vigilancia de las fronteras. Sin embargo, a veces no son suficientes estos indicadores para explicar el impacto en relación de los escenarios micro regionales, puesto que está en función de la magnitud y modalidades, el perfil demográfico regional y las características de los individuos. Estos efectos no se refieren únicamente a la recomposición y estructuración sociodemográficas, sino también a la modificación de las condiciones socioeconómicas, políticas y culturales, en total repercusión en lo personal y familiar.

Edelia Villarroya (2015), propone cuatro parámetros para explicar el impacto 1) el número de individuos, los que migran y los receptores generando cambios a partir de la "percepción de seguridad y control en el poder de decisión (que cambia) según el tamaño percibido, aunque no necesariamente manejan el poder sociopolítico las mayorías numerales". 2) El tiempo de exposición al impacto: el tiempo de permanencia del inmigrante y el de exposición al contacto de los autóctonos con otras culturas. Entre más tiempo se queden en espacios receptores, más cambios se generan. 3) Los efectos transitorios o permanentes se valoran a partir de las diferencias intergeneracionales, 4) La distancia geográfica, lingüística y cultural: a mayor distancia mayor diferencia entre la cultura de origen y la de acogida, genera mayor shock cultural.

Villarroya (2015), recupera el modelo la teoría de Hofstede, las “cinco dimensiones útiles para comparar las culturas entre sí: distancia al poder, individualismo/colectivismo, masculini$\mathrm{dad} /$ feminidad, tolerancia a la incertidumbre y proyección vital a corto o largo plazo. Estas sirven para la comparación cultural y entender que a mayor distancia, se requiere mayor esfuerzo por las culturas en contacto y es necesaria una mayor plasticidad en sus individuos"(Villarroya, 2015). De las cinco dimensiones, la del individualismo/colectivismo es la más pertinente para evaluar el impacto del cambio aculturativo, cercana al concepto de apoyo social percibido y a la necesidad de un sentido de pertenencia que pone en la mirada las diferencias en la manera de afrontar el miedo a lo desconocido y a la inseguridad que provoca la soledad, y todo esto tanto para los que emigran como para los que reciben. En el estudio de las discrepancias culturales es imprescindible la aportación de Geert Hofstede (1978), en la Teoría de las Dimensiones Culturales que explica el porqué de las actitudes de rechazo en la interacción con personas de otras culturas y da marcos para examinar los procesos de percepción de las diferencias culturales, y especialmente esa visualización de otras culturas que aparentemente parecen comportarse y pensar de modo diferente.

En el encuentro del receptor y el migrante, ocurren diversos fenómenos que se ha estudiado desde la multi y la pluriculturalidad: la integración social del inmigrante es multidimensional y abarca sentidos que van desde lo jurídico hasta lo cultural. En ello se establecen lógicas de interrelación entre distintos grupos, consigo mismos y con las sociedades receptoras. En tal proceso se configuran de manera compleja nuevas formaciones culturales, respecto a lo que suele definirse como pertenencia o identidad. Para Lestage, (2001) hay fases sedentarias en el movimiento circulatorio de los migrantes las cuales pueden durar algunos meses hasta años; en esos periodos se pueden advertir relaciones de identidad-alteridad, procesos de identificación 
que se dan entre los migrantes. Lestage, asegura que los migrantes en los contextos receptivos combinan el reconocimiento - o a veces la reivindicación - de su identidad y los componentes implícitos. En ese inter se pueden generar procesos de adaptación o bien de inserción: categorías que ayudan a definir las reconfiguraciones o recomposiciones culturales en una dinámica contextual.

Estos marcos de referencia se complementan desde la teoría de la alteridad, fundamentalmente planteada por Emmanuel Levinas, que hace alusión a la conciencia de la diferencia relacionada con la experiencia de lo extraño y ajeno; a partir del encuentro con desconocidas singularidades de otro grupo humano; la alteridad siempre se refiere -en relación con la pertenencia grupal propia- a Otros. Para Levinas (1987) (cit. por González; 2009), el otro se impone de un modo distinto a como lo hace la realidad de lo real; se impone porque es otro, porque esta alteridad incumbe al yo con toda su carga de indigencia y de debilida. Levinas (1993) (cit. por González, 2009) introduce el término reconocimiento concebido como semejante a nosotros y al mismo tiempo, exterior; la relación con otro, que bajo esta mirada es una relación mistagógica.

\section{3.- MÉTODO}

\section{Una mirada desde la etnografía}

Esta narrativa tiene su fundamento en la etnografía, considerada como una "metodología artesanal en la era de la informática, sigue siendo útil para conocer y comprender mundos lejanos, no en términos geográficos como antaño, sino culturales. Hoy las ciencias sociales recurren a este trabajo de campo para explicar nacionalismos, regionalismos, movimientos sociales, culturas de la pobreza y la globalización misma (Guber, 2001)" (cit. por Duplatt, 2018). La mirada etnográfica, realiza una visión holística para descubrir una nuevamente en una reconstrucción, que está allí pero que se oculta y solo puedes ser vista mediante un acercamiento reflexivo de la realidad empírica y la complementariedad teórica con el objetivo de comprender el problema en su totalidad. Así, el objeto de estudio de la investigación etnográfica es el estudio de una nueva realidad que emerge de la interacción de las partes constituyentes, en una búsqueda dentro de su estructura con su función y significado, incluyente de lo práctico y lo teórico.(Ramírez, 2009)

\section{Las narrativas locales}

En estos flujos, que intervienen grupos y escenarios se necesitan narrativas para entender las formas globales a partir de historias locales. Las narrativas no es solo lo que se cuenta, sino lo que se escribe no en el sentido estricto de la función de contar, sino en dejar un texto como evidencia de una mirada y la intención de su incidencia. Las noticias del periódico pueden ser narrativas escritas especialmente cuando el periodista o reportero asume un papel que desecha gran cantidad de información, que incorpora anécdotas, recurre a cifras, a estadísticas, a entrevistas convirtiéndose en un periodismo narrativo; pues reconstruye atmósferas, lugares, personajes; bajo una mirada subjetiva. Van de la mano con la interpretación como componente subjetivo y sus herramientas basicas son la mirada, el análisis y la descripción del periodista

Revista Política, Globalidad y Ciudadanía, Vol. 5 No. 10, Julio - Diciembre 2019, Universidad Autónoma de Nuevo León, Monterrey, México, ISSN 2395-8448. 43-62. http://revpoliticas.uanl.mx/index.php/RPGyC/article/view/123 
que los realiza (Puerta, 2011).

Anne-Catherine Brigida (2016) afirma que, en la era global, es más fácil leer los grandes periódicos del mundo, pero esta "información hace que los periodistas se planteen la pregunta ética acerca de quién cuenta las historias y cómo". Ante la manera sensacionalista y condescendiente con que los medios nacionales elaboran noticias locales, alternativamente se elaboran periódicos comunitarios que cuentan las historias. "no desde la visión de un foráneo, sino desde la perspectiva de quienes viven ahí, sufren y sobrellevan los problemas, pero que también disfrutan de las cosas". (Brigida, 2006).

Es prácticamente un rechazo a una "narrativa estigmatizada por parte de los medios de comunicación". Cinthya Alejandro Pizarro acuña el concepto de "narrativas locales" que, aunque no se refiere a las del periódico; implícitamente nos remite claramente como "representaciones-construcciones de eventos en donde los narradores, son discursos sesgados pero que puedan dar pistas metadiscursivas que orientan a los interlocutores sobre cómo interpretar los eventos narrados". (Pizarro, 2005).

Por otro lado, José Manuel Zorrilla Barroso, en su tesis doctoral afirma que los titulares de las noticias, representan constructos que pueden interpretarse como un insumo narrativo: "Estudiándolos como textos, los titulares también tienen unas cualidades propias, de las que resaltan su carácter imprescindible, su elaboración típicamente colectiva y su distinción icónica"(1996). Por su contenido pueden contener elementos para construir una narrativa general pues como elementos de análisis son "textos autónomos que encabezan las noticias que publica la prensa, identifican el relato informativo, designan los hechos, destacan gráficamente, poseen un lenguaje propio y tienen la misión de llamar la atención de los lectores para que lean los textos informativos..." (p.9). la riqueza de los sentidos y significados son suficiente presupuesto para construir narrativas, como la de este ejercicio de narrar la migración. En pocas palabras "la narrativa está al servicio de hacer visibles las contradicciones, para lo cual se sumerge en el movimiento y trae las voces históricamente relegadas"(Duplatt, 2018).

Se consideraron insumos para este estudio, las narrativas locales, entendidas como las noticias generadas por los reporteros y periodistas de los periódicos locales más importantes de la región; "El orbe" y "El diario del Sur". Considerando dichos documentos susceptibles de análisis, y fuente documental como un "vestigio escrito", son "fuente de observaciones sociales", y "tiene carácter secundario ya que no ofrece los mismos fenómenos sociales que han tenido lugar, sino el resultado de la percepción e interpretación de ellos"(López, 2011). En consecuencia, aunque no nos permite un contacto directo con los hechos", más bien es un instrumento mediato, que permite "ver" a través de ellos la riqueza de la narrativa del contenido nos permite "para estudiar los cambios a través del tiempo" (Lopez, 2011). Ambos periódicos son los más difundidos y leídos por la comunidad y tienen un tiraje de aproximadamente 12,000 ejemplares diarios. Se recopilaron 1321 noticias, cuyo criterio de elección se consideraron aquellos que describieran los hechos suscitados en estos once meses (octubre-2018, septiembre de 2019). Se escogieron 124 titulares de primera plana, 524 de segunda plana y el resto fueron títulos secundarios. 


\section{La construcción de una narrativa}

Una vez construido el corpus de narrativas, las técnicas que se utilizaron para el análisis giraron en torno a la recuperación cronológica de los hechos desde octubre 2018, fecha en que iniciaron las caravanas de centroamericanos hasta las manifestaciones africana, para ello fue necesario establecer la relación entre eventos narrados, para hacer una segunda narrativa, esto fue posible encontrar la constante que marca el hilo cronológico: la evolución del flujo. Para la organización de los documentos se utilizó la metodología de análisis de contenido (Abela, 1960) en los que se ordenaron bajo dos criterios: 1) de manera cronológica; por mes, y 2) la utilidad de la nota para a) eslabonar la crónica, b) integrar datos que comprendan los antecedentes y hechos contextuales y, c) describir los hechos para completar la mirada holística de la narrativa.

Prácticamente, la narrativa se estableció en dos líneas: la cronología de la caravana y el impacto en la cotidianidad. Para la primera, encontramos cuatro ejes para entender lo contradictorio y complejo de este periodo de narrativa: un flujo que evolucionó de la solidaridad al rechazo por la comunidad receptora; de las caravanas masivas de centroamericanos a las caravanas de grupos de africanos; de caravanas en condiciones precarias a los grupos de cubanos con recursos suficientes; $y$, desde una política de solidaridad a una política de contención.

\section{4.- RESULTADOS}

\section{El Una narrativa cronológica: Caravana centroamericana a una comunidad africana atrapada. Un flujo que evoluciona.}

En el análisis cronológico de las narrativas periodísticas, se observa que en tan solo un año se ha dado una metamorfosis en la marea migratoria: Un cambio de la forma; de masiva a grupos pequeños; de centroamericanos a cubanos, africanos y haitianos; de ilegales a legales; de grupos de extrema pobreza a grupos con recursos suficientes. Por otro lado, la política inicial de solidaridad planteada por el presidente López Obrador, a la política de contención dictada por Trump; de actitudes de solidaridad y humanismo hacia una muestra de xenofobia. En esta extraña mutación social de la migración, se puede advertir, por un lado, que el impacto económico en la región receptora se da en dos lecturas: desde una derrama económica, especialmente por los cubanos y los hindúes, así como la proliferación de trabajo de obra hacia un reclamo de la baja de ventas y el turismo; por otro lado, desde la cotidianidad donde se percibe un shock, al ver los espacios públicos ocupados y ver a "otros", con otro lenguaje y otra cultura.

\section{De los valores de solidaridad a las actitudes de racismo y xenofobia.}

Durante las dos primeras caravanas masivas, los habitantes se solidarizaron, los municipios prepararon espacios públicos para descansar; algunas $\mathrm{ONG}^{\prime}$ s los alimentaron y dieron víveres, ropas y hasta dinero. Algunas parroquias fueron acondicionadas, las autoridades municipales y Protección Civil estuvieron pendientes de sus necesidades, habilitando banquetas aledañas y calles improvisadas con carpas. Fueron recibidos con comida caliente, servicio médico, baños, 
regaderas y atención a mujeres y niños; manos humanitarias proporcionaron ropa, agua, entre otras prendas donadas. Existieron casos como el del apoyo humanitario de mujeres solidarias al cocinar más 6 mil tamales añadiendo ropa, agua y jugos. En su caminar pidieron "aventones" a camionetas de cargas que solidariamente los trasladaron en recorridos cortos: fue común ver a decenas "colgados" de ellos. Se suscitaron tragedias como el caso de un adolescente que perdió el equilibrio y falleció al caer, al que llamaron el "primer mártir de la caravana".

Asimismo, fue muy fuerte el rumor de niños que se fueron con otras personas, mientras los padres buscaron sin resultados. Conforme pasaron las siguientes caravanas, los habitantes de los pueblos dejaron de dar apoyo. La policía federal y los agentes de migración iniciaron la persecución de los grupos que se rezagaban para remitirlos a un centro de detención en Tapachula. La cuarta caravana fue la que más sufrió este cambio tan abrupto; fueron escoltados por la Policía Federal desde el ingreso en la frontera y en su recorrido hasta Tapachula; después de una semana de haber partido de Honduras, la mayoría cruzo el río fronterizo Suchiate, para evadir la vigilancia de cientos de policías mexicanos sobre el puente internacional y solo se permitió el paso a mujeres y niños.

Otro grupo decidió esperar en el puente fronterizo para ingresar legalmente, mientras que otros desertaron por temor y cansancio. Durante el recorrido, en medio de un calor intenso, se animaron ellos cantando: "Nadie nos va a detener, si ya nos aventamos al río y ya hicimos de todo para llegar hasta acá, no nos detienen". Constantemente se escucharon los comentarios de ánimo, mientras algunos casos caminaron con dificultad debido a las llagas en sus pies. El contingente llegó después de un recorrido de al menos seis horas en el que soportaron un domingo de intenso calor y con la ayuda de pobladores que ofrecieron comida y agua, e incluso vehículos.

En comunicados oficiales, la Secretaría de Relaciones Exteriores y Gobernación constantemente advirtieron a aquellos que cruzaron por el río serían sujetos a "procesos administrativos", e incluso podrían ser repatriados. Los titulares de los periódicos difundían que personal de la Embajada de México en Guatemala y del Consulado de México en Tecún Umán publicaron la información y requisitos para su ingreso a México. En clara propaganda declararon haber coadyuvado en actividades de hidratación y atención médica a los migrantes; exhibieron los esfuerzos de los gobiernos de Honduras y Guatemala que apoyaron a cerca de 500 personas en el regreso voluntario que decidieron a sus lugares de origen en Honduras.

Durante el recorrido, autoridades de la Policía Federal y del Instituto de Migración ofrecieron autobuses para trasladarse a un albergue habilitado en Tapachula, pero también pidieron someterse a controles migratorios, oferta que rechazaron totalmente. Continuamente en el recorrido los altavoces amenazaron: "no pueden continuar en territorio nacional de manera irregular", "Por favor, regularicen su situación migratoria, pueden tener el refugio, la condición de refugiados, si así lo desean, están en todo su derecho de solicitarla", argumentaban al conminarlos a acudir al albergue. Si bien les aseguraron que podían solicitar asilo o refugio, en comunicados previos el gobierno mexicano advirtió sobre repatriaciones, y la Comisión Nacional de Derechos Humanos (CNDH) señaló que no había certeza sobre lo que pasará con ellos. "Estamos 
cansados, pero no nos vamos a subir a los camiones. Lo que tememos es que nos mientan y nos lleven a una estación migratoria o nos deporten", comentaron al tiempo del rechazo.

Las autoridades insistieron en subir y trasladarlos en autobuses a un albergue habilitado para unas 5 mil personas en el recinto ferial Expo Mesoamericana: la caravana hizo caso omiso y persistieron en su camino con el temor de que al acudir al albergue ya no los dejaran salir ante una especie de centro de encarcelamiento para luego deportarlos. Ya en la ciudad, prefirieron apostarse en el parque central a la espera de definir cuáles serán los siguientes pasos. Otras centenas de personas fueron canalizadas a instalaciones del Instituto Nacional de Migración (INM) en Tapachula, dando prioridad a grupos familiares, en particular con niños, niñas, adolescentes, mujeres, mujeres embarazadas y adultos mayores. Algunas decenas de migrantes cuando expresaron su interés de solicitar refugio fueron trasladados a una instalación para atenderlos por el INM, aunque no detallaron qué pasó con ellos, si fueron retenidas o bien pudieron salir y les concedieron asilo.

En contraparte, muchos migrantes se quedaron varados en Tapachula, pernoctando por semanas enteras en el parque central del centro histórico. Ante ello empezó a surgir un rechazo y la disminución de apoyo de ciudadanos y empresarios aludiendo a la falta de seguridad y bajas ventas, además de actos de inseguridad, violencia, alertas sanitarias; argumentando la violación al estado de derecho y a las leyes mexicanas, pidiendo el retiro del parque y centro histórico. Para marzo, se observó un grupo numeroso apostado en el parque central por tiempo indefinido a la espera de una caravana más numerosa de más de nueve mil migrantes varados entre Ciudad Hidalgo y Tapachula, provocando malestar entre los negocios asociados y organizados. Los comerciantes y empresarios expresaron que los migrantes asentados en el parque se dedicaron a pedir constantemente a los peatones o empezó a aparecer el trabajo sexual irregular; escenario que fue incomodo a los compradores, nacionales o extranjeros, los cuales -para la mirada de los empresarios- han dejado de visitar el centro de la ciudad.

Los periódicos anunciaron que casi el 80 por ciento de un aproximado de dos mil 500 a tres mil guatemaltecos que diariamente visitaban Tapachula para realizar compras dejo de hacerlo, debido a la incomodidad y el aspecto que los cientos de migrantes generaron al asentarse en la ciudad. Los habitantes del centro histórico de Tapachula comenzaron a rechazarlos y pidieron que ser removidos. La Secretaría de Seguridad Pública Municipal recibió el constante reporte de vandalizar en la vía pública, ingerir bebidas alcohólicas en la calle y dejar basura, tipificadas como faltas administrativas. Algunas narrativas de los periódicos recuperaron frases de los pobladores que mostraron una actitud de "nos están invadiendo", "están ocupando nuestros espacios" o bien la de "porque el gobierno no los expulsa", demostrando el rechazo colectivo a los espacios propios de la cotidianidad e identidad local.

Este sentimiento de "distintividad" que supone la ocupación de un territorio es también una manifestación de la identidad personal o grupal. Esta "identidad territorial” o diferenciación del territorio identifica al sujeto consigo mismo y también con los otros y ante los otros; se convierte así en un "espacio defendible" esto sugiere la presencia de rasgos y signos territoriales como conductas y actitudes explicitas por los ocupantes y como disuasión de posibles invasiones, la 
eficacia de los rasgos territoriales depende -además de la calidad física inherente y del significado simbólico- del contexto social en el cual es percibido (Gimenez, 2005). Las conductas xenofóbicas, en este sentido son la indignación y la defensa de los espacios simbólicos de la comunidad receptora.

De caravanas masivas de centroamericanos a caravanas silenciosas e invisibles de cubanos, haitianos y africanos.

Las caravanas de migrantes inicialmente constituidas por centroamericanos fueron realmente éxodos de familias completas, mujeres con bebés en brazos, niños, jóvenes y adultos. Se observaron enfermos en silla de ruedas y un contingente de LGBTI que exhibieron su preferencia sexual y los motivos de su éxodo en pancartas improvisadas. En cuanto a las cantidades no se puede precisar pues solo se tienen datos aproximados: la primera partió de San Pedro Sula, Honduras, y de otros puntos de este país y se inició por unos mil hondureños el 13 de octubre a los que se fueron añadiendo salvadoreños y guatemaltecos hasta llegar entre 7 y 10 mil. Una segunda, de casi de mil hondureños partió de Esquipulas, Guatemala, el 21 de octubre; otras tres caravanas conformadas por salvadoreños, que partieron desde El Salvador en días posteriores, y otra de hondureños que salió de San Pedro Sula el 14 de enero de 2019. En total fueron 6, que fueron diluyéndose por la política de contención que se inició en de abril de 2019.

La migración en caravanas disminuyo en los primeros meses del año, sin embargo, se observó que aumentaron los migrantes cubanos, que de manera silenciosa y casi invisible llenaron los primeros cuadros de la ciudad, la mayoría ilegalmente pidiendo una visa transitoria permanecieron estacionados en espera de obtenerla para llegar a la frontera estadounidense y pedir asilo. En algunos casos los encerraron en la Estación Migratoria Siglo XXI y fueron liberados tras múltiples denuncias sobre las condiciones infrahumanas en que se encontraban lo que provocó la salida de la delegada regional del INM y el despido del personal de la oficina. La mayoría de migrantes pidió apoyo a la Comisión Mexicana de Ayuda Refugiados (COMAR) para iniciar el proceso que permitiese solicitar refugio, esperando así, la decisión de la Secretaría de Gobernación de otorgar la condición de refugiado. Durante todo el proceso de salida del centro de detención, los migrantes contaron con el asesoramiento del Alto Comisionado de las Naciones Unidas para los Refugiados (ACNUR).

En el mes de mayo, cientos de migrantes obtuvieron su permiso correspondiente para transitar por el país, siguieron su destino por avión generando una demanda inusualmente vista. Aunque los cubanos disminuyeron se acrecentó en el año el número de ciudadanos de países como Afganistán, Eritrea, Bangladesh, Nepal, Pakistán, India, China, Nigeria o Brasil, entre otros. La fisonomía de la migración cambio radicalmente, y aparecieron grupos numerosos que llegaron del Congo y Camerún. Se plantaron frente a la Estación Migratoria, para solicitar un permiso para transitar hasta Tijuana, en la espera establecieron una especie de campamento en las banquetas y en terrenos baldíos con casas de campaña y material improvisados. Mientras tanto, comenzaron a hacer colas interminables a las afueras de la COMAR, para pedir asilo en calidad de refugiados, las cuales se pueden observar hasta la fecha. La imposibilidad de atenderlos provoca que se "estacionen" por días, semanas y meses, en espera de pasar a realizar 
el trámite. Allí duermen y realizan sus necesidades básicas. Muchos de ellos solicitan a apoyo al ACNUR, sentados a las afueras en las banqueas esperando su turno por largas horas y días completos. Es muy común observar grandes contingentes concentrados en las calles aledañas, a la COMAR y a la ACNUR; algunas ONG's que extienden algunos documentos de apoyo para la obtención de permisos. El espacio más significativo es el campamento asentando frente al a la Estación Migratoria s. XXI, donde miles están prácticamente pernoctando durante ya más de ocho meses. Este espacio se ha convertido en un lugar autoconstruido y marginal, en el sentido de que no cuenta con todos los servicios, la imagen es evidencia de una agudización de la estigmatización implícita en la atención burocrativa.

Este panorama viene a reconfigurar la formas y maneras del fenómeno migratorio en Chiapas, estado que por su situación fronteriza siempre ha sido espacio de flujos y circuitos de migración, llamado tradicionalmente como un territorio de inmigración, emigración y tránsito (Anguiano, 200), otros lo han denominado migración en ciclos interno, regional e internacional (Villafuerte y García, 2014), esencialmente es una región donde conviven, los que van de paso, los que no pudieron pasar, los que vienen a quedarse, y los que regresan del norte y de centroamericana; sin embargo esta migración africana y afroacaribeña, nunca se ha dado y mucho menos de manera masiva y aguerrida, lo que permite avizorar que en estamos siendo parte del movimiento internacional de migración.

\section{De centroamericanos pobres a cubanos "con dinero”.}

Las caravanas de centroamericanos mostraron la pobreza con las condiciones precarias: cansados, ropas raídas, con hambre, arrastrando bultos de ropa vieja, zapatos desgastados, aceparon todo lo que se les donaba. Muchas caminaron con sus respectivas familias, otros en pareja, madres solteras y madres ancianas. Se observaron enfermos en silla de ruedas, niños espantados con rostros desnutridos. La gran mayoría jóvenes adolescentes que en su lenguaje y expresaron su esperanza para lograr el sueño. Algunos comentaban que tienen familiares "allá" y que los estaban esperando, otros dejaron atrás familia con la esperanza de ayudarles o traerlos consigo. Se entretejieron historias de valor humano, de sueños por conseguir y anhelos que motivan a superar la condición de pobreza, marginación y de riesgo.

A diferencia de los migrantes cubanos; en lugar de pernoctar en albergues prefirieron rentar cuartos económicos de hoteles y en muchos casos se asociaron para rentar casas de seguridad. En la zona norte de la ciudad se pueden observar actualmente colonias habitadas por migrantes cubanos. Son visitantes asiduos de las plazas comerciales y los cafés, esperando pasar el tiempo para conseguir "los papeles" y migrar. A diferencia del centroamericano con una fisonomía peculiar: morenos, bajos de estatura y complexiones robustas: el cubano alto, esbelto y un moreno diferente al lugareño o centroamericano y con un acento claramente identificable provoca que los propios empiezan a sentirse desplazados de los espacios de convivencia pública. Durante los primeros meses agentes de migración iniciaron redadas en las colonias suburbanas donde muchos cubanos y africanos sin papeles fueron encerrados para determinar su situación legal, lo que provocó que cientos de detenidos estuviesen hacinados en la estación migratoria y en varias ocasiones utilizaron la violencia para escapar superando en número a los vigilantes del lugar.

Revista Política, Globalidad y Ciudadanía, Vol. 5 No. 10, Julio - Diciembre 2019, Universidad Autónoma de Nuevo León, Monterrey, México, ISSN 2395-8448. 43-62. http://revpoliticas.uanl.mx/index.php/RPGyC/article/view/123 
El hecho fue de mucha tensión y mientras las colas eran largas, el ambiente fue propicio para exasperar los ánimos y provocó situaciones de reclamo. Algunas expresiones como la de "Estamos huyendo de una dictadura", "Tenemos familia en los Estados Unidos. Pero los mexicanos no quieren ayudarnos" fueron gritos de los que se concentraron para esperar atención frente a la agencia de refugiados mexicanos. Los que tienen acceso a dinero en efectivo pueden recurren a contrabandistas, o coyotes, expertos en eludir los puestos de control, y conocidos por pagar a los funcionarios mexicanos. Sin embargo, los precios para cruzar la frontera ilegalmente pueden ascender a 5.000 dólares o más por persona.

\section{De una política de solidaridad a una política de contención.}

En la conformación de las narrativas, están presentes los discursos de las políticas migratorias, y no se pueden entender las realidades locales sin el contexto discursivo en la implementación, donde actores administrativos, con intereses y hábitos, operativizan decisiones en hechos. La puesta en marcha fue siempre "visible en un discurso institucionalizado, procedimental y burocrático". Considerando que los discursos se dan de acuerdo con el tipo de política que se trata, Lowi (2007) explica que estas puede ser: regulatorias, distributivas, redistributivas y constitutivas. En este caso las políticas regulatorias encontraron en este año el escenario y una arena en un marco institucional y donde mediante discursos evidenciaron el tránsito de un argumento solidario a una de normatividades regulatorias.

Durante los últimos meses de la administración de Peña Nieto, el canciller Videgaray anunció pedir apoyo a la ONU para gestionar las peticiones de asilo. Se anunció que toda persona que ingrese al país de manera irregular será rescatada y sujeta a procedimiento administrativo y, en su caso, será retornada a su país de origen, de manera segura y ordenada. En ese entonces el presidente electo anunció que implementaría un programa para dotar de visas de trabajo a los migrantes centroamericanos, prometió que respetarían sus derechos y ofreció otorgarles permisos de trabajo para incorporarse a proyectos como el Tren Maya. En octubre de 2018, el gobierno anterior envió a 244 elementos de la Policía Federal, anunciando que "no era parar" el avance de la caravana, sino apoyar al INM en la "atención" de los migrantes. Las autoridades ofrecieron asilo o retorno a sus países de origen; sin embargo, la mayoría de los migrantes decidió continuar su camino.

Contradictoriamente, en la cuarta caravana, agentes migratorios mexicanos comenzaron a detener decenas durante el recorrido a los grupos que se rezagaban o se adelantaban. Para la quinta caravana, no se dio acceso por el puente internacional, y el contingente cruzó por el Río Suchiate. Durante la estancia en, el INM se encargó de colocar brazaletes y otorgó "tarjeta de visitante por razones humanitarias" con la cual además de comida, podían acceder a empleo mientras permaneciesen en suelo mexicano. Se ofreció otorgar visas migratorias con el fin de reducir el flujo de personas hacia Estados Unidos. La entrega de documentos legales fue hasta permanecido hasta siete meses realizando trámites; estas Tarjetas de Residente Permanente, Residente Temporal, de Visitante por Razones Humanitarias y de Visitante Regional, fue medida de control y de registro, se incrementó a partir de las políticas de retención, anunciando siempre "tienen que ser previamente aprobados, cumplir con los requisitos legales, además del registro, 
donde firman una documentación y son tomadas huellas dactilares y fotografías, bajo una serie de requisitos, ante la COMAR, el INM y el ACNUR. Aunque la intención explicita fue la regularizar y permitir la estancia legal, se planteó como la atención y servicios brindados a quienes permanecen en un proceso de regularización, que en promedio se tarda aproximadamente siete meses para la respuesta o bien para obtenerla. Los trámites son engorrosos y demasiado burocráticos; acuden a una oficina de regulación, solicitan el acceso con una serie de documentos como condición para otorgar el permiso, las cuales son periodos de espera hasta de ocho meses. Para los cubanos, esto es desesperante, en virtud de que no pueden salir de Chiapas, so pretexto de continuar con otros trámites y estar pendientes de acudir a firmar a las oficinas migratorias, lo cual obliga a una erogación económica no prevista. En tanto centroamericanos que reciben la Tarjeta de Visitante Regional, por un año, solamente pueden circular por Chiapas, Tabasco, Campeche, Quintana Roo y Yucatán, por los acuerdos de autoridades federales, en donde pueden realizar actividades laborales.

Esta situación agudiza a los africanos toda vez que solo quieren un "oficio de salida" para viajar a otros estados o llegar al norte e ingresar a Estados Unidos y muchos casos ni papeles poseen o no reúnen los requisitos exigidos. Como es de esperarse, se niega la petición, quedando en un estado de indefinición: no pueden seguir adelante, no pueden regresar a su país y no es viable para ellos quedarse.

En consecuencia, se genera una crisis que se agrava ante el estancamiento de cientos de ellos, sin que obtengan respuesta en torno a su solicitud de salida. La situación es caótica para muchos, y en consecuencia decenas de africanos iniciaron protestas frente a la Estación Migratoria. Aunque las autoridades mexicanas negociaron un proceso de atención e información realmente no pueden atenderlos sin que llenen los requisitos. Esta situación se complica aún más, en el terreno de las políticas migratorias, toda vez que, a inicio de junio, Estados Unidos y México llegaron a un acuerdo migratorio que evitó que el primer país impusiera aranceles a todos los productos provenientes del segundo. Ante tal presión, se envió a las fronteras norte y sur a la Guardia Nacional -un nuevo cuerpo de seguridad impulsado por el Ejecutivo- y se contrató a más personal migratorio. El Gobierno de México informó que, a raíz del acuerdo, por el cual se desplegó la Guardia Nacional en las fronteras norte y sur, se ha reducido periódicamente el flujo migratorio un $56 \%$. Según datos del INM, en el periodo de enero a septiembre, el gobierno "presume" haber deportado a 106.552 indocumentados.

Algunos migrantes frustrados trataron de escabullirse hacia el norte por etapas, tomando minibuses públicos hasta llegar justo antes de los puntos de control de inmigración, luego caminaron alrededor de las barreras, antes de subirse a otro tipo de transporte en dirección norte. Pero luego son víctimas de ladrones y secuestradores, dando lugar a narrativas que los periódicos cuentan: "Nos atacaron, pero nos las arreglamos para combatirlos y escapar", dijo Teresa Mayadal, de 46 años, una técnica química de La Habana que, junto con su esposo, llegó a la ciudad mexicana de Arriaga, una terminal de tren de carga a unos 150 kilómetros al norte de Tapachula. Sus pies estaban cuidadosamente vendados, como resultado de las ampollas de días de caminar hacia el norte desde la frontera guatemalteca. Sentada a su lado, una hondureña de 21 años con lágrimas en los ojos cuenta, con la voz entrecortada, que había sido agredida sexualmente mien-

Revista Política, Globalidad y Ciudadanía, Vol. 5 No. 10, Julio - Diciembre 2019, Universidad Autónoma de Nuevo León, Monterrey, México, ISSN 2395-8448. 43-62. http://revpoliticas.uanl.mx/index.php/RPGyC/article/view/123 
tras caminaba por un puesto de control, los agresores también robaron su teléfono celular y su bolso: preguntó a algunos visitantes si podía pedir prestado un teléfono para llamar a su novio en Estados Unidos y buscó el equivalente a un dólar para pagar un baño en una casa privada.

Muchas solicitudes han sido denegadas después de meses de espera, y ordenan abandonar el país en cuarenta días, esto ocasiona un doble problema, porque el país más cercano es Guatemala, con menos probabilidad de mejora. Así que deciden quedarse en las inmediaciones de la Estación Migratoria, iniciando una especie centro de concentración voluntaria. Las autoridades no pueden llevarse a todos hasta África y deportarlos, para lo cual los denomina "apátridas", adjetivo que se interpreta que no sabe qué hacer con ellos.

El cambio en el discurso que se dio por el presidente López Obrador antes y después de asumir su responsabilidad como presidente, ha sido decisivo en la evolución y el impacto de la migración en esta región fronteriza. La política de contención está siendo el muro que no se construyó en el norte pero que finalmente se levantó aquí en el sur y que lejos de ser de ladrillos y cemento, es un muro de exceso de burocracia. Los habitantes de este lado del muro están construyendo una realidad ineludible la de compartir un territorio migrante con centroamericanos y africanos, generada por políticas de contención cuyos formuladores también configuran los términos del discurso al combinar el vocabulario, la retórica y el simbolismo de las intenciones políticas.

\section{Impacto en la cotidianidad}

\section{La sobrepoblación y la vida cotidiana.}

Las narrativas periodísticas, afirman que en Tapachula habitan alrededor de 80 mil migrantes que se encuentran en espera de una resolución de su solicitud de refugio. Por otro lado, en la estación migratoria se mantienen alojadas aproximadamente a 900 personas entre ellos menores de edad. La sobrepoblación migratoria ha provocado que otros cientos de migrantes se manifiesten afuera de la estación, bloqueando el acceso principal y exigiendo a las autoridades que se les permita transitar libremente por el país. Hasta el momento de los 80 mil migrantes, solo existen 21 mil solicitudes de refugio.

Frente a la cifra que podría aumentar hasta 55 o 60 mil que llevan un proceso para su solicitud; afuera de la estación migratoria se observan todos los días largas filas esperando ser recibidos para hacer el trámite. Tapachula se ha vuelto una pequeña ciudad internacional y llena de cultura de cientos de países de todo el mundo. La vida en las calles es de espera: sentados, platicando y yendo de un lugar a otro resolviendo su situación migratoria. Además, se ha vuelto parte de la economía que fluye en los pequeños negocios del lugar. Migrantes de Haití, Honduras, el Salvador, Cuba y África conviven discretamente enriqueciendo las calles con su cultura, su gastronomía y sus idiomas. Muchos toman trabajos temporales como obreros, cocineros y en otras posiciones de servicios para ayudar a comprar comida y alquilar viviendas baratas. Una docena o más de personas a menudo viven hacinadas en habitaciones individuales, durmiendo en colchonetas y mantas. Los migrantes se reúnen diariamente bajo la sombra de los árboles en la plaza central de Tapachula, a la espera de las limosnas. Al final de la calle del centro de 
inmigración Siglo XXI, un barrio de chozas de haitianos y africanos en su mayoría a la espera de los papeles de salida ha brotado, dando a la zona una clara identidad afrocaribeña.

En esa cotidianeidad se van construyendo historias que van narrando los periódicos. Por ejemplo, el de una mujer centroamericana que atiende un hostal, que llegó a México y consiguió un empleo, en su narrativa dice que ama al país desde que llegó, porque muchos como ella, logaron obtener un trabajo en la ciudad, lo que les permite tener un ingreso, además colaboran cotidianamente para que la estancia de otros migrantes sea positiva en un contexto de violencia y xenofobia que se vive en el país.

Otro caso es el de Selma Etelvina Hernández, mejor conocida como Mama África, ella aprendió a preparar comida cubana y africana para los migrantes. Comenzó a tener clientes provenientes de Somalia, quienes le pidieron preparar comida como la de lugar natal. Ellos comparan los condimentos y se los dan a Mama África para que ella cocine y pueda tener comida preparada como en sus países, aunque no sepa igual se están combinando los sabores y sazones para generar nuevos guisados. Otra narrativa, es el nacimiento del primer niño de padres africanos que mantuvo un paro de 20 días a las afueras de la Estación Migratoria Siglo XXI quienes solicitan los oficios de salida. Ellos viven en el campamento improvisado en casas de campaña con temperaturas que superan los 36 grados centígrados por la mañana y fuertes aguaceros por las tardes. Muanda, el padre le puso por nombre Manuel López Obrador, con la esperanza que con su nacimiento en tierras mexicanas puedan obtener sus documentos para poder viajar al norte del estado.

\section{Derrama económica.}

Las narrativas destacan que en las calles los pequeños comerciantes se encuentran en los migrantes un consumidor constante y seguro, incluso hay quienes aseguran "cuando no hay muchos migrantes se viene abajo el negocio" específicamente aquellos que se dedican a la venta de chip y celulares en el centro de la ciudad; desde que comenzaron a llegar, hay una creciente en las ventas de líneas telefónicas y de otros productos. El grupo de migrantes que se mantienen en el centro, aseguran gastar más de 10 mil pesos cuando llegan a esta ciudad, en la compra de alimentos, ropa, zapatos y otros artículos de primera necesidad.

Por otro lado, los empresarios especialmente del centro dicen que la llegada de los migrantes ha incrementado la inseguridad; perciben una mala imagen que proyecta Tapachula a nivel nacional especialmente en el ingreso violento de migrantes centroamericanos. Los empresarios en el ramo turístico cuentan que se han visto seriamente afectados debido a que no existen las condiciones necesarias para que lleguen visitantes nacionales a esta región Soconusco. Algunos indican que por razones de inseguridad prefieren "cerrar temprano sus comercios, o viven con un miedo constante de ser asaltados". Para ellos el ingreso masivo de migrantes africanos, cubanos y centroamericanos, se vive con zozobra con el temor de ser violentado cuando se va al centro; se sienten inseguros al acudir a los bancos y a comprar en los comercios del Centro, además que empaña el trabajo realizado para impulsar y promocionar los lugares naturales de la región, pues ha caído el arribo de turistas. Las narraciones aluden a las formaciones de colonias 
enteras de migrantes que han preferido quedarse a vivir en esta ciudad; y al no existir condiciones de generación de empleo se agrava la situación, además que se ha cancelado el proyecto de zona económica especial en Puerto Chiapas.

\section{Una estancia que atrapa.}

En su llegada los migrantes centroamericanos buscaron un lugar para permanecer en Tapachula, en lo que expiden las tarjetas, llegaron y se asentaron en el parque central Miguel Hidalgo, la situación se agravó porque fueron llegando más personas. Los albergues estuvieron a su máxima capacidad y aunque autoridades implementaron espacios, los migrantes ante el temor de ser deportados encontraron el parque central un espacio seguro para acampar, además que siendo el centro de la ciudad siempre está protegido por la policía y eso hace sentir seguro. Algunos activistas constantemente pidieron a las autoridades que establecieran un lugar para la comunidad migrante de manera temporal; mientras que le están entregando las tarjetea que permite tener acceso para el tránsito o empleo, o bien para seguir su camino a los Estados Unidos.

Las noticias periodísticas escogieron deliberadamente a portavoces de diversas asociaciones civiles y empresariales, que exigieron al gobierno que atienda la problemática como una situación sanitaria, considerando la presencia de una población flotante que tenía que ser atendida con medidas de prevención sanitaria y además demandó la improvisación de lugares para que realizar las necesidades básicas. El panorama que exhibieron son situaciones de contaminación al aire libre, y ante la falta de recursos económicos, se convirtieron en indigentes pidiendo para su alimentación; algunos pronunciamientos fueron xenofóbicos que exigieron la expulsión o la deportación. Estas expresiones y demandas fueron acompañadas de quejas de los habitantes y visitantes del centro por el desaseo en los espacios que habitaron. Manifestaron que las personas ya no acudieron al centro o al parque Bicentenario ante un mal olor existente.

Esto se incrementó desde el 7 de junio cuando se firmó un acuerdo con Estados Unidos por el que México se comprometió a incrementar la presión sobre los migrantes a cambio de que Washington no impusiese aranceles a las exportaciones. Desde entonces, la Guardia Nacional se desplego y se multiplicaron las detenciones y deportaciones. Según datos de la Secretaría de Relaciones Exteriores, el flujo de migrantes se redujo cerca de un $40 \%$ en el mes de julio. Entre las historias narradas se encuentra de un camerunés, que, como cientos de compañeros sin papeles, llegó a Chiapas y se entregó al INM para tener los servicios básicos; pasó una semana encerrado y cuando recibió el oficio de salida se le calificó como "apátrida" a pesar de reconocer que su nacionalidad es camerunesa, le explicaron que esto ocurre porque el consulado de su país no respondió a los requerimientos de México para ser reconocido. Pero en realidad, ese adjetivo se entendía de que no será deportado porque no hay a donde llevarlo, sin embargo, en un oficio anexo se le instruye a regularizar su situación, que, en caso contrario, tendrá que abandonar el país por su frontera sur.

En ese sentido la frase "por su frontera sur" es ya una amenaza de expulsión, puesto que antes de la implementación de la política de contención los migrantes recibieron el oficio en el que 
tenían que dejar México, pero no se determinaba por dónde, así que aprovecharon los 20 días que determina la temporalidad para llegar al norte y pedir asilo en Estados Unidos. Muchos los cuales muchos con el dinero suficiente se trasladaron en avión hasta Tijuana. Esto llevó a que, equivocadamente, el oficio de salida fuese comúnmente conocido como "salvoconducto". Este mecanismo fue empleado por migrantes procedentes de todas las partes del mundo: cameruneses, haitianos y cubanos, sin embargo, esto ha cambiado y en consecuencia los ciudadanos de diversos países de África, Asia o el Caribe no tienen opciones para abandonar Chiapas desde entonces.

Las instrucciones para el INM, sobre el oficio de salida "con fines de regularización" indican que "no otorga una condición de estancia", sino la posibilidad de legalizar su situación si cumple con la ley; además, específica que "con dicho documento las personas extranjeras no pueden transitar libremente por territorio nacional”, incluyen las reglas para abandonar el país. "En concordancia con lo establecido en la fracción IX del artículo 240 del Reglamento de la Ley de Migración, la persona extranjera que obtenga este beneficio y no presente el trámite correspondiente en el plazo que le fue señalado, deberá abandonar territorio nacional dentro del mismo plazo a través de un lugar destinado al tránsito internacional de personas en la frontera sur más cercano al lugar donde se expidió el citado documento". Esta referencia a la frontera sur aparece en los oficios de salida que migrantes, como el camerunés mencionado, vienen recibiendo en las últimas semanas.

Constantemente se comenta que el gobierno ya no dará pases a migrantes de forma masiva, por lo que ha planteado a los extracontinentales que regularicen su estancia, ya sea reubicándose o pedir asilo, pero el permiso para transitar definitivamente no llegará. Muchos africanos están empecinados en el oficio de salida sin aceptar otra prerrogativa. De aceptar la propuesta del Gobierno Federal de establecerse implica planear el apoyo a los africanos a establecerse en no solo en Chiapas sino en los estados del sur en donde implicaría crear empleos, acceso a la salud y educación. Sin embargo, para el sentido de vida de muchos ellos es solo el paso para ir al norte solo un pequeño grupo de africanos aceptó y fueron llevados a las Costas de Oaxaca. Los titulares plantean ya una propuesta: "Piden que a migrantes les den el salvoconducto o que los deporten" o bien "Migrantes deben aceptar propuesta de establecerse en estados del sur".

El panorama que se viven con el fortalecimiento del control migratorio, la necesidad de conseguir recursos económicos para la subsistencia ante una prolongada estancia temporal en este espacio de tránsito, y la imposibilidad o el no deseo de regresar a los países de origen, se está traduciendo en largos tiempos de permanencia en Tapachula de una comunidad africana en tránsito. Estas situaciones promueven que Tapachula deje de ser un territorio de tránsito para convertirse en destino temporal o permanente ante las actuales solicitudes de refugio.

\section{5.- DISCUSIONES}

Considerando la premisa de que todo flujo migratorio trae consigo un impacto y como tal un cambio en las estructuras tanto de los receptores como de los que se desplazan, en los flujos migratorios que se están dando en la región del sur de Chiapas, particularmente en Tapachula, 
la migración el análisis es obligado desde una lectura cultural como potencial para la transformación normativa y desde una perspectiva estructural con sus ingredientes demográficos y económicos.

Considerando que la propuesta de los niveles en los estudios sobre el cambio que se ubican en el micro nivel de los individuos y las familias, el meso nivel de las comunidades y las regiones, y el macro nivel de los Estados nación y la economía global (Massey et al., 1998; Portes, 1999) (cit. por Portes, 2009).; las narrativas anteriores plantean cuatro posibles líneas para generar un análisis micro y meso nivel en dos direcciones: por un lado, en el sentido antropológico en la emergencia de conductas propias de la enculturación y bien por otro, desde los efectos de las políticas de contención migratoria.

En primer lugar, se observa por parte de la comunidad receptora, una "invasión" de migrantes que nunca se había visto, y aunque la migración centroamericana fue parte de la "normalidad", nunca se había visto caravanas masivas irrumpiendo y ocupando los espacios que le dan identidad cívica al tapachulteco, provocando una reacción xenofóbica argumentada con el descuido de los espacios públicos. En segundo lugar, la presencia de africanos es vista también como una invasión, no tanto al espacio, sino a la cultura y a la identidad. Alejandro Portes (2009) le llama "movimientos telúricos", que vienen a desestabilizar en una baja intensidad las estructuras de poder asentados en los "planos institucionales" y los "planos simbólicos" generalmente dibujados en la cotidianidad de las comunidades.

En tercer lugar, la política de contención migratoria, desde un análisis geopolítico, se puede considerar en términos hipotéticos como la concreción del muro que había planteado Trump: todo parece indicar que el discurso de una política de considerar a México de ser un "tercer país seguro", se concretiza de en la creación de una "región segura", flanqueada por un "muro burocrático" que está obligando al nacimiento de una comunidad a desarrollar una cultura para vivir de este lado del muro. Y finalmente en cuarto lugar, el efecto Trump es el nacimiento de una comunidad africana en consecuencia de las políticas de contención que no permiten el tránsito regular: los migrantes acusan que el documento de tránsito que ofrece los obliga a salir solo por la frontera sur de México y ya no les permite llegar al norte.

Si bien, toda migración representa el lugar de destino como el objetivo final de la movilidad, esto implica iniciar una etapa de integración que va desde la regularización migratoria hasta los mecanismos de sustento; ¿Cómo se darían en estas fases, en un país que no es el destino, pero que obligados se tendrían que adaptar? ¿Cuáles serían los efectos, costes políticos y económicos para la región?

\section{5.- CONCLUSIONES}

En términos antropológicos, las narrativas sobre la migración en el sur de Chiapas contienen el ingrediente que traen consigo una recomposición de la vida cotidiana. Los habitantes de Tapachula, en su vida diaria se están acostumbrando a ver a largas filas de migrantes, en su mayoría centroamericanos, frente a las oficinas de las agencias de refugiados. 
Este movimiento está implicando varios cambios, incluidos los lugares de convivencia cotidiana, de trabajo y de consumo, significa que existe una ruptura en el ámbito individual o social, en tal vía implica un aprendizaje social en términos internacionales e interregionales, creando nuevas relaciones, nuevas solidaridades y un nuevo capital social y aunque no corresponde a una ruptura total, si se puede acudir al concepto llamado transnacionalismo o el de comunidades transnacionales. (Peixoto, 2007). Prueba de ello es la cotidiana multitud políglota de África, Asia y el Caribe que se reúne regularmente en la sede local del INM y la agencia de asuntos migratorios. Los tapachultecos conviven con los que se encuentran atrapados en una creciente represión de las autoridades mexicanas y abandonados en esta asfixiante ciudad del sur. Los migrantes no pueden continuar sin arriesgarse a ser detenidos, y permanecen en Tapachula juntando la documentación para viajar legalmente.

Las historias narradas, cuentan como el aumento en este año del número de migrantes junto con los puestos de control a lo largo de la carretera costera y obviamente la estrategia mexicana es previsible tanto que el hecho de colocar puntos de contención en las carreteras tiene como sentido acorralarlos y detenerlos en el sur. Ante la necesidad de propuestas, la secretaria de Gobernación planea crear un cinturón de contención en el Istmo de Tehuantepec, el punto más estrecho para evitar que avance hacia el norte.

El escenario en Chiapas está cambiando la atmósfera de los meses pasados, cuando decenas de miles de centroamericanos -tanto en caravanas organizadas como en pequeños grupos- se movieron libremente por la zona. A muchos se les concedieron rápidamente visas humanitarias como parte de la promesa del presidente López Obrador de ayudar a los migrantes. La alfombra de bienvenida ha sido retirada y en la carretera costera, agentes de inmigración, la policía federal y oficiales militares exigiendo a los pasajeros documentos, los que carecen y no demuestran su estatus legal son escoltados a las camionetas de inmigración.

Las voces representativas expresan preocupadamente que los migrantes que llegan a Tapachula, no tienen otra opción que quedarse y solicitar documentos de inmigración - visados, permisos de visitante temporal, estatus de refugiado o documentos de salida que dan a los beneficiarios 30 días para salir de México. Convirtiéndose en una tortuosa y asfixiante espera.

La demanda abruma a la burocracia migratoria, que además tiene recortes presupuestarios. La agencia de refugiados del país espera que las solicitudes se dupliquen este año en comparación con las del año pasado. Mientras que los centroamericanos representan la mayoría de los migrantes, un gran número de los llamados extracontinentales de todo el mundo también han hecho el viaje. La percepción de esta realidad es el reconocimiento y la aceptación que existe otra sociedad y para "los otros", y "estar aquí" es vislumbrar para ellos un nuevo horizonte social, lo que significa que tiene lugar un "cambio subjetivo radical" (Peixoto, 2007), es decir una ruptura y a una revolución en la vida cotidiana; lo que permite comprender que los migrantes en su travesía demuestra que no están resignadas a su condición social.

Los habitantes de esta ciudad también están aprendiendo a vivir en represión y un desplie-

Revista Política, Globalidad y Ciudadanía, Vol. 5 No. 10, Julio - Diciembre 2019, Universidad Autónoma de Nuevo León, Monterrey, México, ISSN 2395-8448. 43-62. http://revpoliticas.uanl.mx/index.php/RPGyC/article/view/123 
gue planeado de la Guardia Nacional, esto ha generado protestas contra la militarización de la frontera sur de México al estilo estadounidense, que se comparan con los intentos de Trump de construir un muro a lo largo de la frontera entre ese país y Estados Unidos, creando una realidad nueva en tan solo un año.

\section{REFERENCIAS}

A Abela, J. A. (1960). Las tecnicas de analisis de contenido: una revisión actualizada. Fundacion Centro de Estudios Andaluces. Universidad de Granada, 43(2), 296. https://doi. org/10.2307/334486

Anguiano Téllez, María Eugenia. (2008). Chiapas: territorio de inmigración, emigración y tránsito migratorio. Papeles de población, 14(56), 215-232. Recuperado en 18 de noviembre de 2019, de http://www.scielo.org.mx/scielo.php?script=sci_arttext\&pid=S1405$74252008000200010 \& \operatorname{lng}=\mathrm{es} \& \operatorname{tlng}=\mathrm{es}$.

Aruj, R. S. (2008). Causas, consecuencias, efectos e impacto de las migraciones en latinoamérica. Papeles de Poblacion, 14(55), 95-116. Recuperado de http://www.scielo.org.mx/scielo. php?script $=$ sci_arttext\&pid=S1405-74252008000100005\&lng=es\&nrm=iso\&tlng=es

Bautista, M. (2019, septiembre 20). Extrancontinentables sin Opciones Deberán Salir por Guatemala: INM. Periodico El Orbe, p. 1. Recuperado de https://elorbe.com/ portada/2019/09/20/extrancontinentables-sin-opciones-deberan-salir-por-guatemala-inm. html

Detel, W. (2015). Social Constructivism. International Encyclopedia of the Social \& Behavioral Sciences: Second Edition. https://doi.org/10.1016/B978-0-08-097086-8.63081-7

Duplatt, A. E. (2018). Narrativas. revista patagónica de periodismo y comunicación. Recuperado el 12 de octubre de 2019, de Narrativas website: https://www.narrativas.com.ar/etnografiay-periodismo/

Giménez, G. (2005) Territorio e identidad. Breve introducción a la geografía cultural, En: Trayectorias, vol. VII, núm. 17, enero-abril, 2005, pp. 8-24 Universidad Autónoma de Nuevo León Monterrey, Nuevo León, México.

Gonzalez, Fredy. (2009) Aleraidad y su itinerario desde las perspectivas multidisciplianarias. en Rev. Reflexiones 88 (1): 119-135, Recuperado de: https://www.redalyc.org/ pdf/729/72912559009.pdf

Hofstede, G., (1978). The Poverty of Management Control Philosophy. The Academy of Management Review, 3(3): 450-461

Peixoto, J. (2007). Migración y cambio social: efectos y retos de la inmigración en Europa del Sur. En: Recerca, revista de pensament i anàlisi, núm. 7. 2007. - pp. 105-126. Recuperado en: http://www.e-revistes.uji.es/index.php/recerca/article/view/182/167

Lestage, F. (2001). La “adaptación” del migrante, un compromiso entre varias representaciones de sí mismo. Scripta Nova: Revista electrónica de geografía y ciencias sociales, (5), 16. https://doi.org/10.1344/sn2001.5.341 
Lopez, F. (2011). El análisis de contenido como método de investigación. XXI: Revista de Educación, 4(2002), 167-179. Recuperado de http://uhu.es/publicaciones/ojs/index.php/ xxi/article/viewArticle/610

Lowi, T. (2007), Políticas públicas, estudios de caso y teoría política. En Aguilar, L., La hechura de las políticas, México, Porrúa,

OIM. (2018). Principios y Objetivos del MGdM. Recuperado de https://publications.iom.int/ es/system/files/migof_brochure_sp.pdf

Pizarro, C. A. (2005). Representar a las narrativas locales: los efectos políticos de las etnografías acerca de los subalternos. Studia Politicae, 06(2), 91-103. Recuperado de http://revistas. bibdigital.uccor.edu.ar/index.php/Prueba2/article/view/593/666

Portes, A. (2009) Migración y cambio social: algunas reflexiones conceptuales. En RES n 12 (2009) pp. 9-37. Recuperado de http:/www.fes-sociologia.com/files/res/12/01.pdf

Puerta, A. (2011). El periodismo narrativo: una manera de dejar huella de una sociedad en una época. Anagramas Uniiversidad de Medellin, 9(18), 47-60. Recuperado de http://www. scielo.org.co/pdf/angr/v9n18/v9n18a04.pdf

Ramírez, M. de J. (2009). La investigación desde la mirada de la etnografía. ETHOS EDUCATIVO, 28(septiembre-diciembre), 19-24. Recuperado de http://imced.edu.mx/ Ethos/Archivo/28-19.pdf

Villafuerte Solís, Daniel, \& García Aguilar, María del Carmen. (2014). Tres ciclos migratorios en Chiapas: interno, regional e internacional. Migración y desarrollo, 12(22), 0337. Recuperado en 18 de noviembre de 2019, de http://www.scielo.org.mx/scielo. php?script=sci_arttext\&pid=S1870-75992014000100001\&lng=es\&tlng=es

Villarroya, E. (2015). The social impact of human mobility: An undivided vision of cultural and individual change. Metode, (5), 51-56. https://doi.org/10.7203/metode.81.3269

Zorrilla Barroso, J. (1996). El titular de la noticia (Facultad de Ciencias de la Información. Universidad Complutense de Madrid). Recuperado de https://eprints.ucm.es/1865/1/ T20884.pdf 